\title{
Diastrophic Dwarfism
}

\author{
D. W. WILSON, A. R. CHRISPIN, and C. O. CARTER \\ From Royal National Orthopaedic Hospital; The Hospital for Sick Children, Great Ormond Street; \\ and the Clinical Genetics Research Unit, Institute of Child Health, London
}

The distinctive features of diastrophic dwarfism are micromelia, a normal head, scoliosis, club foot, and joint contractures (Lamy and Maroteaux, 1960). Some 40 cases have been identified. Lamy and Maroteaux (1960) described 3 and noted 11 others in earlier published reports. Subsequently additional cases have been described by Kaplan et al. (1961), Taybi (1963), Stover, Hayes, and Holt (1963), Langer (1965), Paul et al. (1965), McKusick and Milch (1964), Rubin (1964), and Amuso (1968).

It is important to establish the diagnosis of diastrophic dwarfism. Of 8 patients seen by the authors, 2 have died in infancy from aspiration pneumonia and respiratory failure. Long-term survival is associated with severe dwarfism and an ultimate height of about $140 \mathrm{~cm}$. There is a continuing need for clinical help during development in order to minimize the handicap from joint contractures, dislocations, club feet, and scoliosis. In spite of such care it is likely that a severe physical handicap will occur. Some of these patients have a cleft palate and some have swellings in the ears. Parents require advice on the genetic hazard. The purpose of this paper is to illustrate these points by reports of 4 patients.

\section{Case Reports}

Details are recorded of trunk and limb measurements in Table I, of ranges of joint movements in Table II, and of severity of scoliosis in Table III.

Case 1. A boy (Fig. 1) was delivered after surgical induction at full term in 1953. The mother had been large during pregnancy and had slight toxaemia. The patient was an only son of unrelated parents aged 22 and 20 years.

At 1 month of age the patient was thought to be achondroplastic. Both ears had curious cysts (Fig. 2) which were aspirated and later incised, releasing a serosanguinous fluid. Bilateral talipes equinovarus was treated with Denis Browne splints for one year with little benefit. At the age of 3 he had, in each foot, a crescentic resection of the talus and a tendon transfer (tibialis anterior to peroneus brevis).

Received July 9, 1968.
When aged 4 years he had marked flexion contractures at both hips $\left(45^{\circ}\right)$ and both knees $\left(50^{\circ}-70^{\circ}\right)$. Traction produced some improvement and he had walking calipers fitted. Bilateral supracondylar osteotomy was performed in his sixth year.

The equinus deformity steadily increased to $45^{\circ}$ at 11 years of age, and he required a bilateral elongation of the Achilles tendon and wedge tarsectomies. This resulted in plantigrade feet.

In 1966 , the boy was $12 \frac{1}{2}$ years old and obese (weight $40.5 \mathrm{~kg}$., height $1.15 \mathrm{~m}$.). He was able to shuffle slowly with hips and knees bent. However, he could ride a child's tricycle with ease. He needed special boots. The limbs were very short, and there was limitation of movement at all major joints, with flexion contractures of hips, knees, elbows, and wrists. The

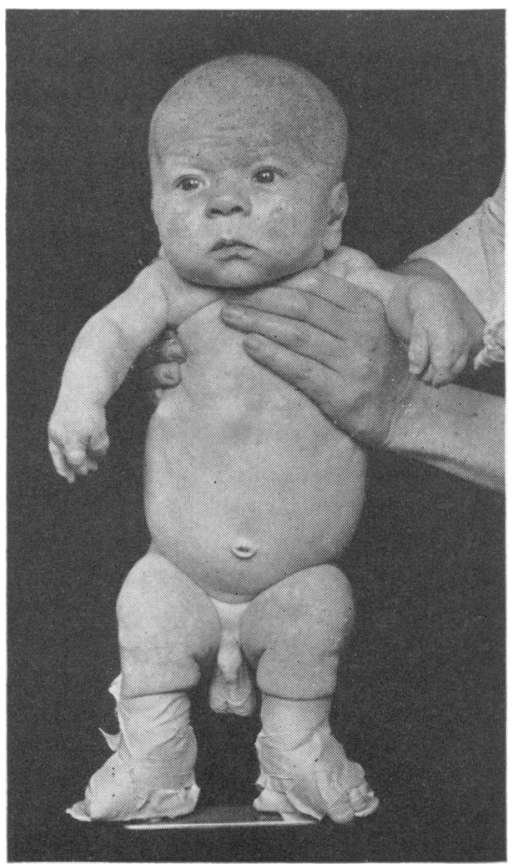

FIG. 1.-Case 1 at age 6 weeks. Achondroplastic proportions but normal head. 
Diastrophic Dwarfism

TABLE I

Clinical Measurements (cm.)

\begin{tabular}{|c|c|c|c|c|c|c|c|c|}
\hline & \multicolumn{4}{|c|}{ Case No. and age } & \multirow{2}{*}{$\begin{array}{c}1 \text { (12 yr. } 4 \text { mth.) } \\
114 \cdot 5 \\
75 \cdot 0 \\
71 \cdot 0 \\
43 \cdot 0 \\
100 \cdot 5\end{array}$} & \multirow{2}{*}{$\begin{array}{c}2 \text { (3 yr. } 2 \text { mth.) } \\
77 \cdot 5 \\
52 \cdot 0 \\
47 \cdot 0 \\
30 \cdot 5 \\
68 \cdot 5\end{array}$} & \multirow{2}{*}{$\begin{array}{c}3 \text { (11 yr. } 7 \text { mth.) } \\
98 \cdot 0 \\
72 \cdot 0 \\
61 \cdot 0 \\
45 \cdot 5 \\
109 \cdot 0\end{array}$} & \multirow{2}{*}{$\begin{array}{c}4(3 \mathrm{yr} .) \\
68 \cdot 5 \\
43 \cdot 0 \\
40 \cdot 5 \\
28 \cdot 0 \\
61 \cdot 0\end{array}$} \\
\hline $\begin{array}{l}\text { Standing height } \\
\text { Sitting height } \\
\text { Vertex-pubis } \\
\text { Pubis-heel } \\
\text { Span (medii) }\end{array}$ & $\begin{array}{l}\cdots \\
\cdots \\
\cdots \\
\cdots\end{array}$ & $\begin{array}{l}\cdots \\
\cdots \\
\cdots \\
\cdots\end{array}$ & $\begin{array}{l}\cdots \\
\cdots \\
\cdots \\
\cdots \\
\cdots\end{array}$ & $\begin{array}{l}\cdots \\
\cdots \\
\cdots \\
\cdots \\
\cdots\end{array}$ & & & & \\
\hline \multicolumn{4}{|c|}{$\begin{array}{l}\text { Upper limb (acromion-medius) } \\
\text { Arm alone (acromion-lat. epicondyle) } \\
\text { Forearm (lat. epicondyle-radial styloid) }\end{array}$} & $\begin{array}{l}\cdots \\
\cdots \\
\cdots\end{array}$ & $\begin{array}{l}39 \cdot 5 \\
18 \cdot 0 \\
14 \cdot 5\end{array}$ & $\begin{array}{r}26 \cdot 5 \\
12 \cdot 5 \\
9 \cdot 0\end{array}$ & $\begin{array}{l}47 \cdot 0 \\
19 \cdot 0 \\
18 \cdot 0\end{array}$ & $\begin{array}{r}25 \cdot 5 \\
11 \cdot 0 \\
9 \cdot 0\end{array}$ \\
\hline \multicolumn{5}{|c|}{ 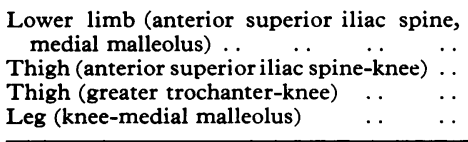 } & $\begin{array}{l}52 \cdot 0 \\
24 \cdot 0 \\
26 \cdot 5 \\
24 \cdot 0\end{array}$ & $\begin{array}{l}42 \cdot 0 \\
19 \cdot 0 \\
20 \cdot 5 \\
10 \cdot 0\end{array}$ & $\begin{array}{l}45 \cdot 5 \\
25 \cdot 0 \\
25 \cdot 5 \\
20 \cdot 5\end{array}$ & $\begin{array}{l}29 \cdot 0 \\
15 \cdot 0 \\
16 \cdot 0 \\
13 \cdot 0\end{array}$ \\
\hline \multicolumn{6}{|c|}{ Standing height of normal child of same } & $94 \cdot 0$ & $142 \cdot 0$ & $93 \cdot 0$ \\
\hline
\end{tabular}

TABLE II

Joint Movements

\begin{tabular}{|c|c|c|c|c|}
\hline Case No. and age & 1 (12 yr. 4 mth.) & 2 (3 yr. 2 mth.) & 3 (11 yr. 7 mth.) & 4 (3 yr.) \\
\hline $\begin{array}{c}\text { Shoulder: gleno-humeral abduction } \\
\text { external rotation }\end{array}$ & $\begin{array}{ll}R & 80 \\
\text { L } & 30\end{array}$ & $\begin{array}{ll}R & 80 \\
L & 80 \\
R & 80 \\
L & 40\end{array}$ & $\begin{array}{ll}\text { R } & 70 \\
\text { L } & 80 \\
\text { R } & 90 \\
\text { L } & 90\end{array}$ & $\begin{array}{ll}\mathrm{R} & 90 \\
\mathrm{~L} & 90\end{array}$ \\
\hline $\begin{array}{l}\text { Elbow: flexion } \\
\text { extension }\end{array}$ & 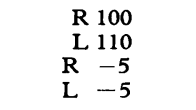 & $\begin{array}{r}R \quad 160 \\
L \quad 160 \\
R-10 \\
L-10\end{array}$ & $\begin{array}{ll}R & 170 \\
\mathrm{~L} & 170 \\
\mathrm{R} & -5 \\
\mathrm{~L} & \mathbf{0}\end{array}$ & $\begin{array}{lr}R & 170 \\
L & 160 \\
R & 0 \\
L & -5\end{array}$ \\
\hline $\begin{array}{l}\text { Wrist: flexion } \\
\text { extension }\end{array}$ & $\begin{array}{rr}R & 40 \\
L & 40 \\
R & 0 \\
L & -5\end{array}$ & $\begin{array}{ll}\mathbf{R} & 90 \\
\mathrm{~L} & 90 \\
\mathbf{R} & 90 \\
\mathrm{~L} & \mathbf{8 0}\end{array}$ & $\begin{array}{rr}R & 100 \\
L & 100 \\
R & 90 \\
L & 80\end{array}$ & $\begin{array}{ll}\mathbf{R} & \mathbf{7 0} \\
\mathbf{L} & 90 \\
\mathbf{R} & 90 \\
\mathbf{L} & 90\end{array}$ \\
\hline $\begin{array}{l}\text { Fingers: (ext.-flex.). } \\
\text { Metacarpo-phalangeal joints max. range } \\
\text { Metacarpo-phalangeal joints min. range } \\
\text { Proximal interphalangeal joint max. range† } \\
\text { Proximal interphalangeal joint min. range }\end{array}$ & $\begin{array}{r}90-40 \\
80-10 \\
10-70 \\
0-0\end{array}$ & $\begin{array}{r}70-40 \\
0-40 \\
0-80 \\
0-0\end{array}$ & $\begin{array}{r}90-90 \\
90-30 \\
40-90 \\
0-90\end{array}$ & $\begin{array}{r}120-140 \\
90-100 \\
60-100 \\
10-90\end{array}$ \\
\hline $\begin{array}{l}\text { Hip: flexion } \\
\begin{aligned} \text { extension } \\
\text { abduction }\end{aligned}\end{array}$ & $\begin{array}{r}\mathbf{R} 100 \\
\mathbf{L} 100 \\
\mathbf{R}-60 \\
\mathbf{L}-60 \\
\mathbf{R} 30 \\
\mathrm{~L} 30\end{array}$ & $\begin{array}{rr}\mathbf{R} & 100 \\
\mathbf{L} & 120 \\
\mathbf{R} & -60 \\
\mathbf{L} & -60 \\
\mathbf{R} & 20 \\
\mathbf{L} & 30\end{array}$ & $\begin{array}{rr}R & 160 \\
L & 160 \\
R & -10 \\
\text { L } & -10 \\
\text { R } & 30 \\
\text { L } & 30\end{array}$ & $\begin{array}{lr}\mathbf{R} & 150 \\
\mathbf{L} & 150 \\
\mathbf{R} & 0 \\
\mathbf{L} & 0 \\
\mathbf{R} & 80 \\
\mathbf{L} & 80\end{array}$ \\
\hline $\begin{array}{r}\text { Knee: flexion } \\
\text { extension }\end{array}$ & $\begin{array}{r}R 130 \\
L \quad 140 \\
R \quad-60 \\
L-60\end{array}$ & $\begin{array}{l}R 110 \\
L 110 \\
R-10 \\
L-10\end{array}$ & $\begin{array}{l}R \quad 60 \\
L \quad 60 \\
R+30 \\
L+30\end{array}$ & $\begin{array}{r}\mathbf{R} 160 \\
\mathbf{L} 160 \\
\mathbf{R}-5 \\
\mathbf{L}+30\end{array}$ \\
\hline $\begin{array}{l}\text { Ankle: dorsiflexion } \\
\text { plantarflexion }\end{array}$ & $\begin{array}{l}\mathbf{R}-30 \\
\mathbf{L}-20 \\
\mathbf{R} 30 \\
\mathbf{L} 20\end{array}$ & $\begin{array}{lr}\mathbf{R} & -5 \\
\mathbf{L} & \mathbf{0} \\
\mathbf{R} & 30 \\
\mathbf{L} & 20\end{array}$ & $\begin{array}{ll}\mathbf{R} & 10 \\
\mathbf{L} & 10 \\
\mathbf{R} & 30 \\
\mathbf{L} & 20\end{array}$ & $\begin{array}{ll}R & 20 \\
L & 30 \\
R & 60 \\
L & 60\end{array}$ \\
\hline
\end{tabular}

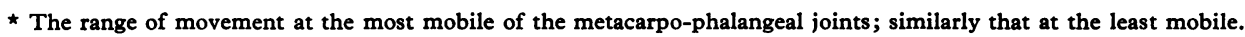

+ The range of movement at the most mobile of the proximal interphalangeal joints; similarly that at the least mobile. 
TABLE III

Scoliosis: Side of Convexity and Angle of Curve as Measured by Cobb's Method (1948)

\begin{tabular}{|c|c|c|c|c|}
\hline Case No. & Age (yr.) & Levels & \multicolumn{2}{|c|}{ Curve } \\
\hline 1 & $\left\{6 \frac{1}{2}\right.$ & T4 - T6 & Right & $18^{\circ}$ \\
\hline 2 & $\begin{array}{l}37 / 12 \\
2 / 12\end{array}$ & $\begin{array}{l}\text { T6 -T9 } \\
\text { T10-L1 }\end{array}$ & $\begin{array}{l}\text { Left } \\
\text { Right }\end{array}$ & $\begin{array}{l}14^{\circ} \\
16^{\circ} \\
\text { Nil }\end{array}$ \\
\hline $\begin{array}{l}3 \\
4\end{array}$ & $\left\{\begin{array}{l}13 \\
11 \\
3\end{array}\right.$ & $\begin{array}{l}\text { T4 -T10 } \\
\text { T4 -T } 10 \\
\text { T9-T12 }\end{array}$ & $\begin{array}{l}\text { Right } \\
\text { Right } \\
\text { Left }\end{array}$ & $\begin{array}{l}44^{\circ} \\
84^{\circ} \\
29^{\circ}\end{array}$ \\
\hline
\end{tabular}

proximal interphalangeal joints were stiff in extension, but the metacarpo-phalangeal joints were mobile, though mainly into hyperextension. The index and little fingers showed a curvature inward toward the central fingers. The thumbs were implanted into the palm more proximally than normal, and were mobile. Opposition carried the thumb to midpalm at the base of the little finger, with the interphalangeal joint of the thumb straight. The spine showed a mild right thoracic and lumbar scoliosis with minimal flank rotation, but no lumbar lordosis. The pinnae were irregular, thickened, and hard. The palate was high, but not cleft. The head and skin were normal.

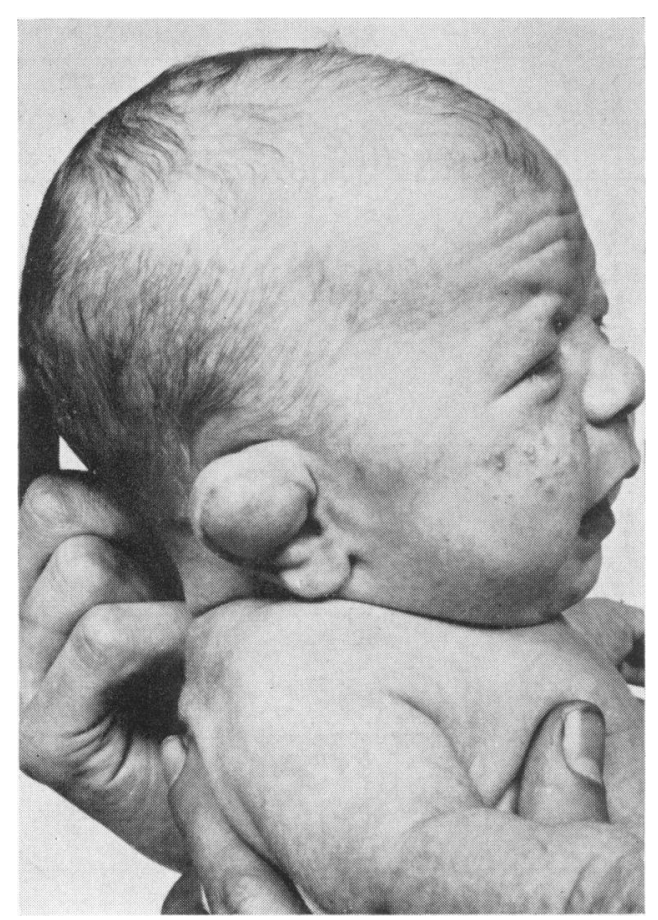

FIG. 2.-Case 1 at age 3 weeks. Cyst of right pinna.
Case 2. A girl, weighing $3.3 \mathrm{~kg}$., was born in 1962 . Pregnancy had been uneventful apart from some hyperemesis. The father and mother were not related and were aged 31 and 27 years, respectively. The mother had had one previous miscarriage and there was one normal sister born in 1956.

At birth the child was noted to have short limbs, bilateral talipes equinovarus, and a cleft palate. There was good movement at all joints except the wrist and fingers, and these were stiff at the proximal interphalangeal joints. The thumbs were abducted and mobile. A tentative diagnosis of achondroplasia with arthrogryposis was made.

At the age of 4 weeks, a translucent cyst in the left pinna was aspirated. The club feet were treated with Denis Browne splints from birth for 5 months, but correction was unsatisfactory. When aged 1 year bilateral soft tissue corrections were performed, and these were followed by elongation of the Achilles tendons. The child was able to sit at the age of 6 months and to walk at about 2 years. Further elongation of both Achilles tendons had to be performed, and a series of plaster of Paris casts was applied to the feet. The palate was satisfactorily repaired at 2 years 9 months.

At 3 years and 2 months (Fig. 3 ) the child weighed $12 \mathrm{~kg}$., and was $78 \mathrm{~cm}$. tall. The limbs were short and there was limitation of movement at the shoulders, elbows, hips, and knees, with fixed deformities. The fingers were stiff in extension at the proximal interphalangeal joints, but very mobile at the metacarpophalangeal joints. There was some lateral curve of the little finger. The thumbs arose from the hand more proximally than usual, were widely abducted, and very mobile (Fig. 4). Opposition was possible to the base of the little finger, with the interphalangeal joint of the thumb straight. The child used the hands dextrously. The feet showed no varus deformity, but there was a slight residual equinus deformity of $5^{\circ}$ on the right. She walked well in ordinary shoes. The spine showed a slight right thoracic scoliosis, and a lumbar lordosis when standing. The head, chest, and skin were normal. The pinnae of the ears showed a curious thickened, crumpled appearance, with two round, hard lumps within the cartilage on the left side (Fig. 5).

Case 3. A boy was born in 1954, after a pregnancy in which the mother had been 'larger' than usual. The father and mother were not related and were aged 30 and 24 years, respectively. There was one normal brother born in 1952 and one normal sister born in 1957.

At 16 days of age bilateral talipes equinovarus, cleft palate, and 'pigeon chest' were noted. When aged 18 months a thoracic scoliosis was observed for the first time: subsequently its severity increased and a Milwaukee brace was fitted. Bilateral coxa vara was noted. In his third year bilateral Brockman's operations on the feet and the first stage of a palatal repair were performed. In his fourth year the palatal repair was completed. When he was $11 \frac{1}{2}$ years old he weighed $23.2 \mathrm{~kg}$. and was $98 \mathrm{~cm}$. tall (Fig. 6). He was 


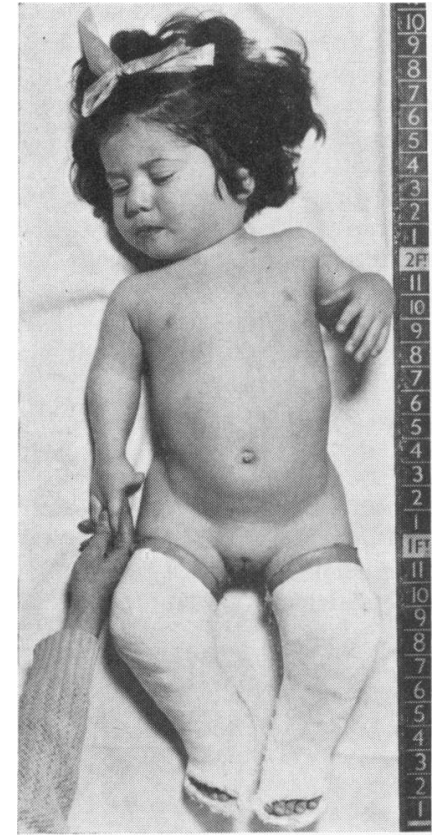

Fig. 3.-Case 2 at age 23 years. Achondroplastic proportions, but normal facies. Deformities of knees and feet.

near the top of his class at a school for the physically handicapped. He was able to run, but walked with a Trendelenberg gait. The limbs were short. Joint movements were not much limited apart from hips, knees (flexion), and one elbow. There was marked joint laxity, especially at the knees ( $30^{\circ}$ hyperextension) and at the metacarpo-phalangeal joints of the fingers. The thumbs were only slightly proximally implanted

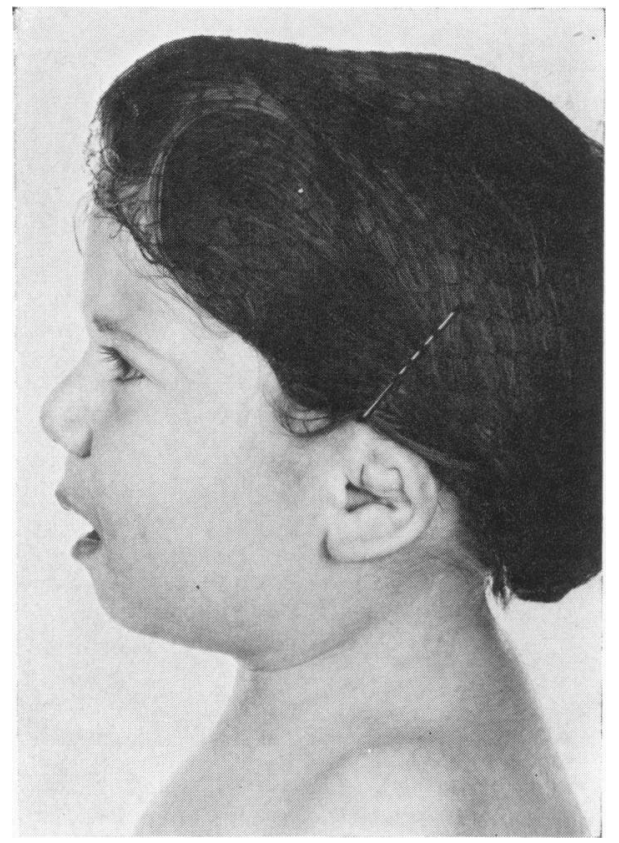

FIG. 5.-Case 2. Deformity of left pinna.

into the palm, but were mobile, opposing to the base of the little finger with the interphalangeal joint of the thumb straight. The fingers were not laterally curved. At the hips the Trendelenberg test was positive. There was no residual equinovarus deformity of the feet, which were broad and short, but not particularly stiff. He had to wear special shoes, to get sufficient width. There was a right thoracic scoliosis with slight kyphosis,

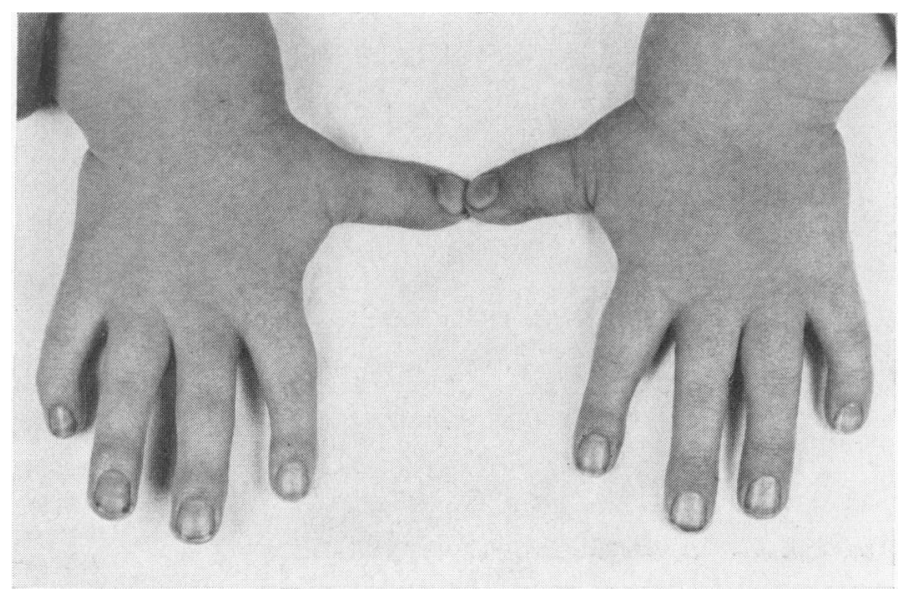

FIG. 4.-Case 2. Abducted, proximally sited thumbs; curved little fingers. 


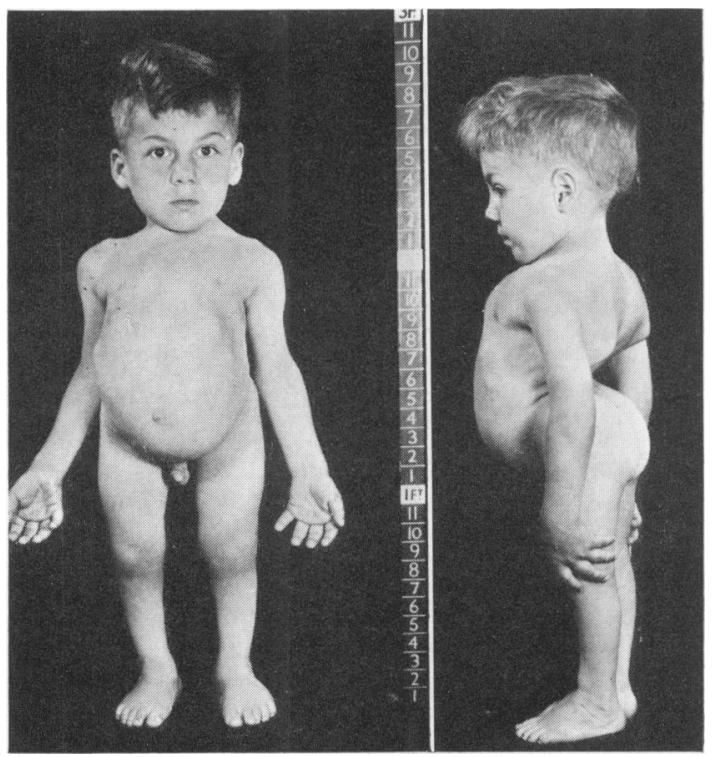

FIG. 6.-(a) and (b). Case 3 at age 8 years. Short stature, normal head, gross lumbar lordosis. associated with a slight left lumbar scoliosis and a gross lumbar lordosis (with pelvic inclination of $40^{\circ}$ ). The lumbar lordosis could be corrected by voluntary effort. The head and ears were normal and the palate repair sound but immobile.

Case 4. A girl, weighing $2 \cdot 2 \mathrm{~kg}$, was born in 1963 after a normal pregnancy. She was an only child. The father and mother were unrelated and were 25 and 27 years, respectively. She was noted to have short limbs, mild talipes equinovarus, and congenital dislocation of the left hip. The deformities were treated in plaster of Paris casts. At 2 years of age the hip was reduced, but the right knee was noted to be dislocated.

At 3 years, the child was $69 \mathrm{~cm}$. tall. There were few joint contractures (one elbow and one knee). Indeed, the joints were generally hypermobile (left knee hyperextension $30^{\circ}$, and a range of movement at the metacarpo-phalangeal joints of up to $260^{\circ}$ ), and the

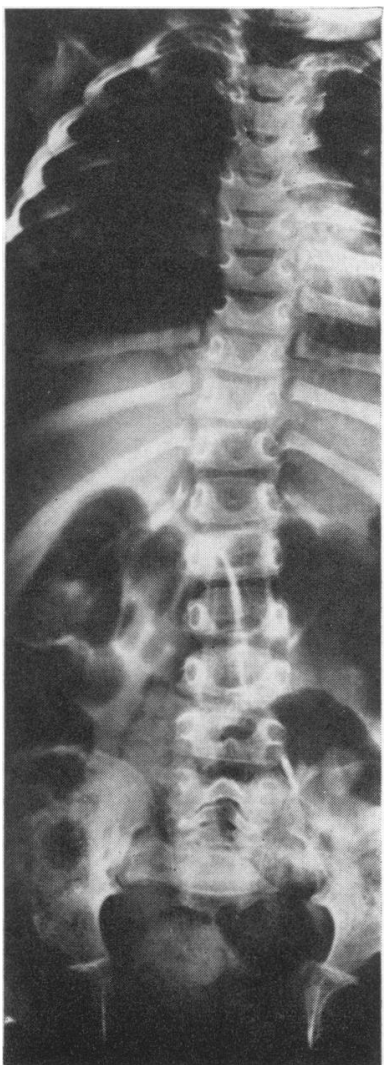

Fig. 8.-Case 2. Thoracic and lumbar spine at age $2 \frac{3}{4}$ years. Very slight scoliosis. The lumbar interpedicular distances do not show tapering typical of achondroplasia.
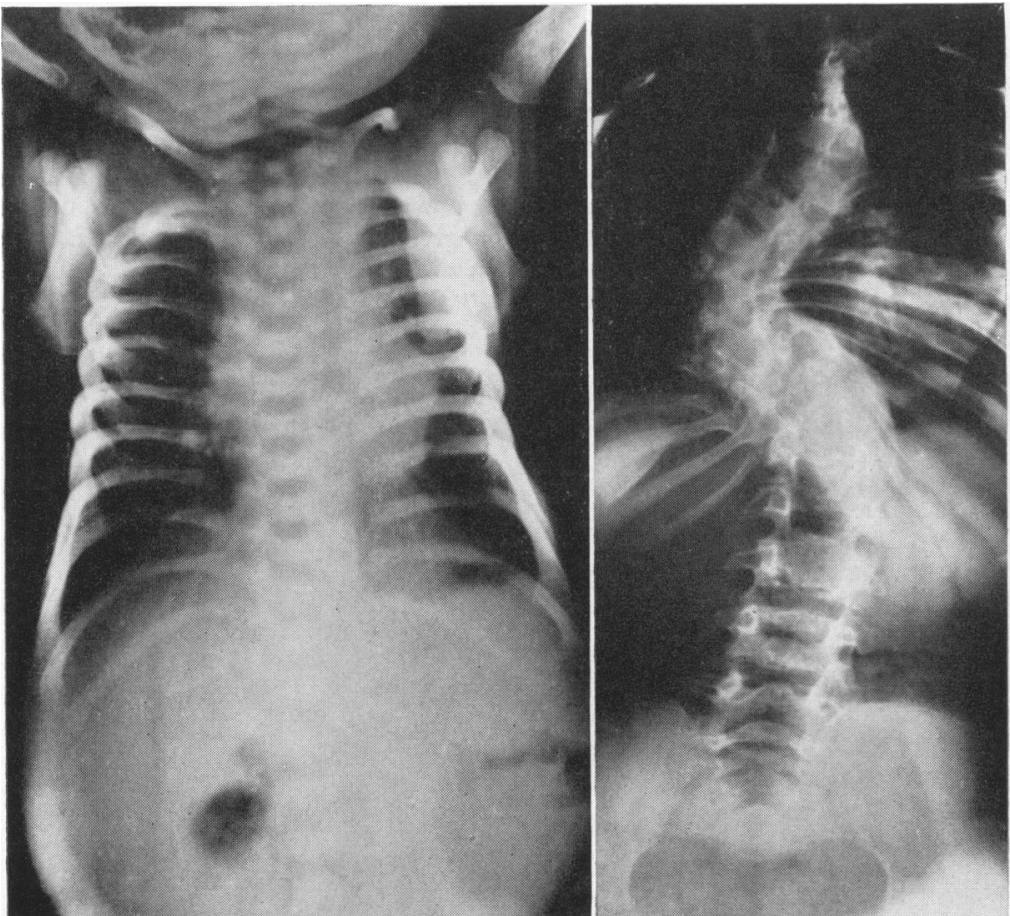

FIg. 7.-Case 3. (a) Thoracic spine at age 1 month. No scoliosis. (antero-posterior) at age 12 years. Thoracic curve of $84^{\circ}$. (b) Spine 
thumb would oppose to a point halfway down the hypothenar eminence. The thumb was proximally sited on the palm, but there was no finger curvature. The feet showed no equinovarus deformity. There was a slight left thoracic spinal curve. The head was normal and the ears were soft and floppy.

\section{Radiological Features}

Radiological features present in any one patient depend on the age of the patient and on the extent to which abnormal development has occurred. Thus, a variation in appearances between different patients can be observed.

Spine. Scoliosis is not present at birth but it can sometimes become quite severe (Fig. 7). One patient (Case 2) had a failure of ossification of the odontoid and minor subluxations at the C 2-3-4 level. Anomalies of segmentation and development of vertebral bodies can occur (Case 3). Mild flattening of some cervical and dorsal vertebrae has been noted. Measurement of interpedicular distances in the lumbar region shows that the caudal narrowing of the canal seen in achondroplasia is absent, and the canal shows identical widths at all lumbar levels (Fig. 8). There is no narrowing of the sagittal diameter of the spinal canal.

Pelvis and hips. The acetabular roofs are flat and there is some 'squaring' of the ilia. However, the deep sacrosciatic notches seen in achondroplasia have been absent. There is delay in the appearance of the femoral capital epiphysis, and its subsequent development is poor (Fig. 9). Dislocation of the hip (Fig. 10) or coxa vara (Fig. 11) may occur.

Limbs. (Fig. 10 and 12.) The diaphyses are short, the proximal limb bones (e.g. humerus) being less short than the distal bones (e.g. radius and ulna). There is some metaphysial widening and radiolucent zones may be seen in the metaphyses. There may be progressive deformity of the epiphysial plate into a chevron outline at the distal ends of the femur, and angulation between the distal radial and ulna epiphysial plates can occur. In general terms those epiphyses whose development is delayed and which show abnormal irregular development are those that partake in the major limb articulations. The other centres, such as those of the trochanters, develop relatively normally. Dislocation (Fig. 10) may be seen.

Hands and feet. In the foot, talipes deformity is found and the deformity may be severe (Fig. 13).
The thumb is set low on the carpus, with deformity of the first metacarpal. There is delay in appearance of secondary centres for metacarpals, metatarsals, and phalanges. Accelerated carpal centre development occurs (Fig. 14). The bones of the carpus and tarsus may show a ring-like outline.

\section{Discussion}

Though the complete syndrome of a diastrophic dwarfism is rare, it is a unique combination of deformities not seen in any other bone dysplasia. The diagnosis is relatively easy to establish once the condition is known. Differentiation from superficially similar forms of dwarfism, especially achondroplasia, is important because of the greater morbidity, the difficulties of management, and the very different genetic prognosis for the parents. Other conditions that may appear to have some superficial resemblance to diastrophic dwarfism include spondylo-epiphysial dysplasia (both Morquio's disease and the pseudo-achondroplastic variant).

Classification. Clinical examination of these 4 patients suggests that among them there is a variable degree of joint contracture. Summation of the joint movements in Table II (except for shoulder abduction for which information was incomplete) confirmed this impression and indicated that there were two subdivisions of the syndrome, namely, the 'stiff' and 'lax' types (Table IV). Cases 1 and 2 are relatively stiff and Cases 3 and 4 relatively lax.

Previously recorded cases are apparently of the 'stiff' variety. However, the patients who are in the 'lax' subdivision have all the essential criteria for the diagnosis.

TABLE IV

Sum of Joint Motions and Contractures

\begin{tabular}{lrr|r|r|r|r}
\hline \multicolumn{2}{c|}{ Case No. } & 1 & 2 & 3 & 4 \\
\hline $\begin{array}{l}\text { Crude sum of free } \\
\text { motions }\end{array}$ & $\ldots$ &.. & 1280 & 1560 & 2040 & 2540 \\
$\begin{array}{l}\text { Crude sum of } \\
\text { tractures }\end{array}$ & $\ldots$ & con- & -305 & -165 & -25 & -10 \\
\hline Arithmetical sum & & 975 & 1395 & 2015 & 2530 \\
\hline
\end{tabular}

Arithmetical sum under 2000 in 'stiff' types, and over 2000 in 'lax' types.

Prognosis. As far as stature is concerned, the outcome for these children is poor. All are likely to be no more than $140 \mathrm{~cm}$. in height. Two of Lamy and Maroteaux's cases aged 17 years and 


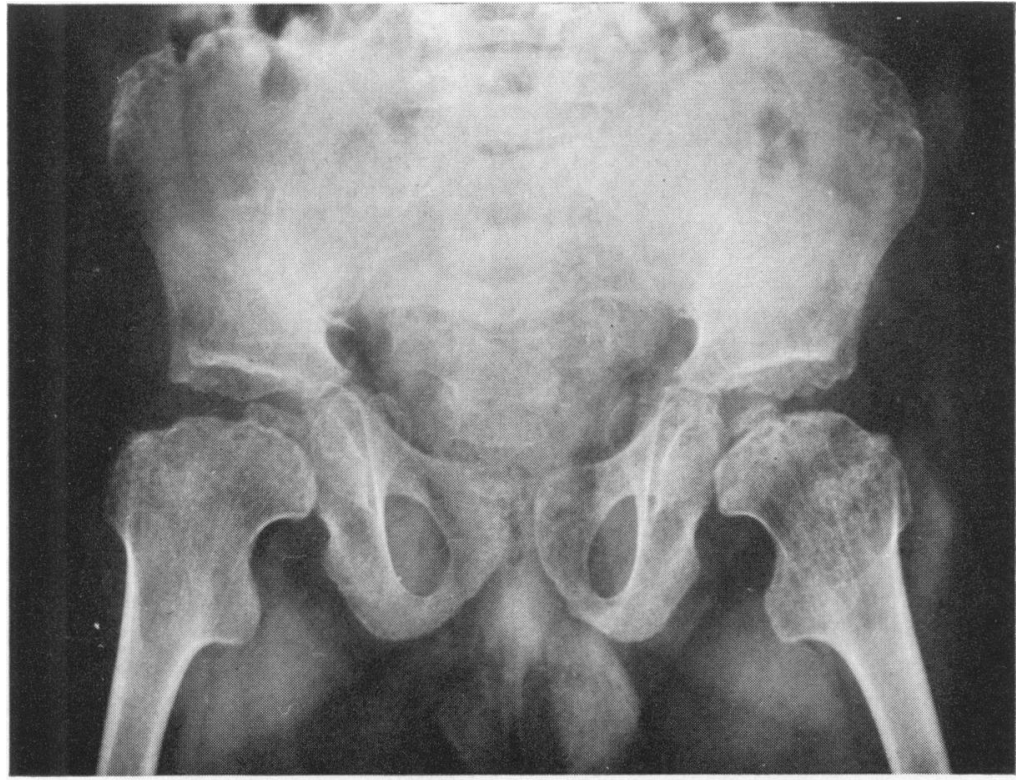

a

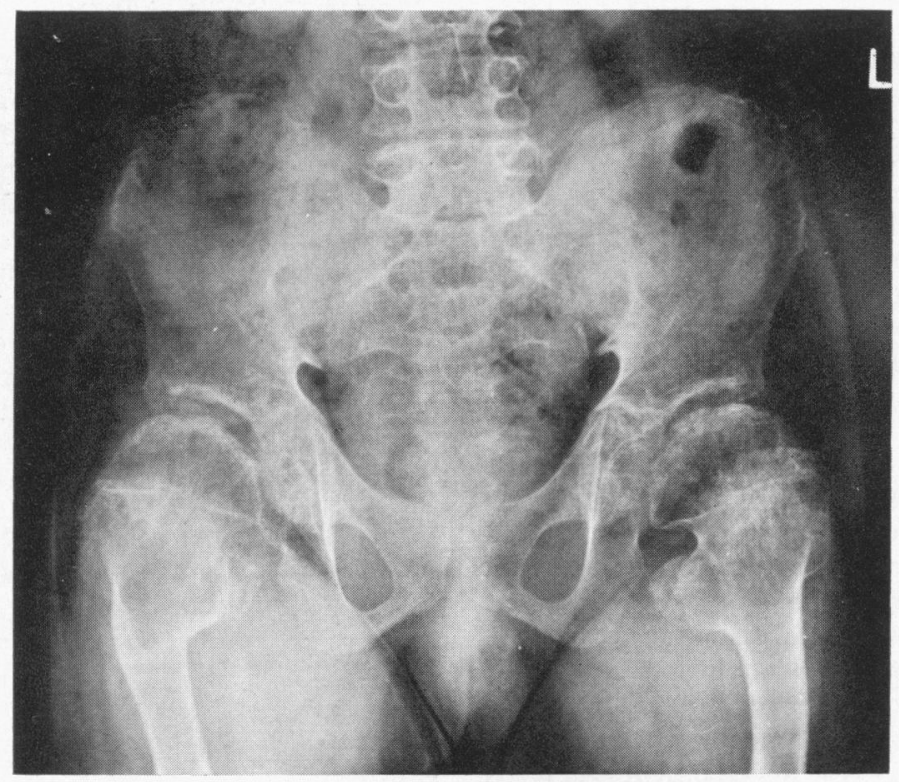

b

(b) At age $11 \frac{1}{2}$ years.

Fig. 9.-Case 1. (a) Pelvis and hips at 4 years 4 months. Capital ossific centres are small. Capital ossific centres are fragmented and the metaphyses misshapen.

22 years, were, respectively, $106 \mathrm{~cm}$. and $119 \mathrm{~cm}$. tall. Paul's patient aged 14 years was $117 \mathrm{~cm}$. in height, about the same as our oldest child (Case 1) at 12 years.
The scoliosis seems to vary in severity. One of our children (Case 3) progressed with time to a severe curve and needed a Milwaukee brace. The other 3 had only moderate curves. The worst 
scoliosis occurred in the 2 'lax' cases; and the youngest (Case 4) is already showing evidence of progression.

The prognosis for disability is much worse in the 'stiff' type. One boy (Case 1) was extensively crippled by recurrent and intractable joint deformities, and this was made worse by his obesity. He weighed $20 \mathrm{~kg}$. more than a normal 6-year-old of $114 \mathrm{~cm}$. height, and roughly what he would have weighed had he been a normal 121 -year-old of $147 \mathrm{~cm}$. height. The prognosis in the 'lax' type of patient is better as far as function is concerned: Cases 3 and 4 had plantigrade feet after treatment for talipes equinovarus, and there were minimal peripheral joint deformities.

Genetic aspects. In their description, Lamy and Maroteaux suggested that the condition was transmitted as an autosomal recessive trait. Instances of two sibs affected have been reported by Helweg-Larsen and Mørch (1945), Catel (1951), Jackson (1951), Kratz (1956), Lato, Severi, and Ceccarelli (1957), and Lamy and Maroteaux (1960). Parental consanguinity was present in the families reported by Helweg-Larsen and Mørch (1945), and since Lamy and Maroteaux's paper, in those of Taybi (1963) and Paul et al. (1965). This present series was compatible with, but provided no additional evidence for, autosomal recessive

Fig. 10.-Case 4. Lower limbs. Dislocation of right knee and left hip.

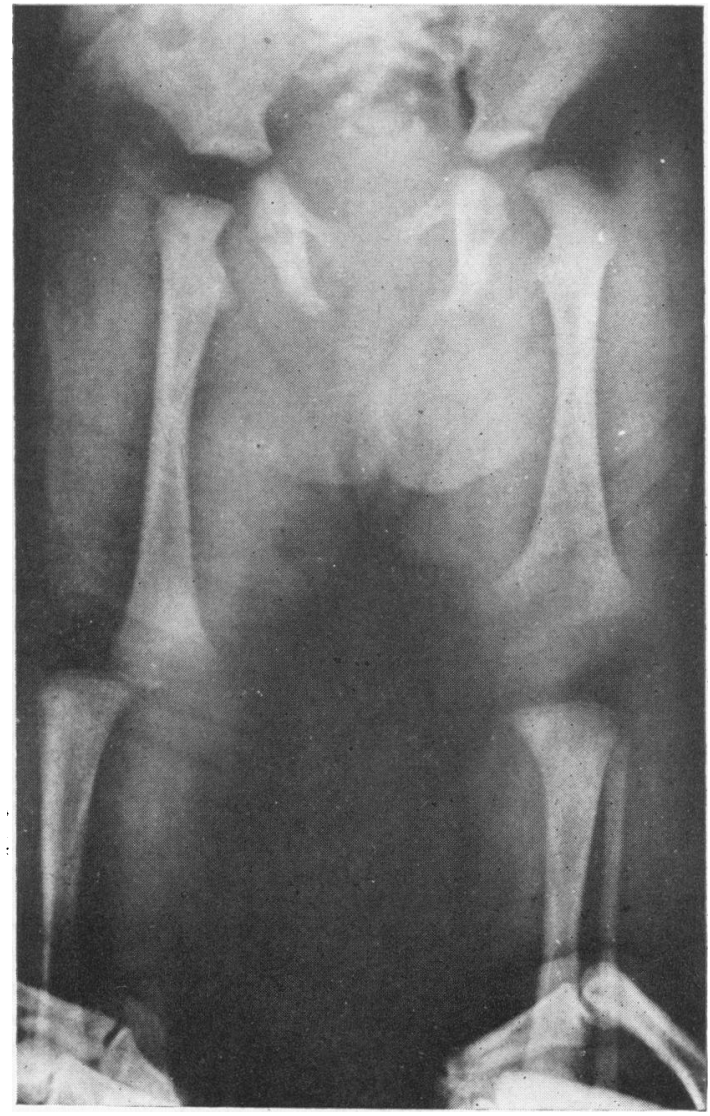

Fig. 11.-Case 3. Pelvis and hips at age 11 years. Extreme coxa vara. Good development of greater trochanters.

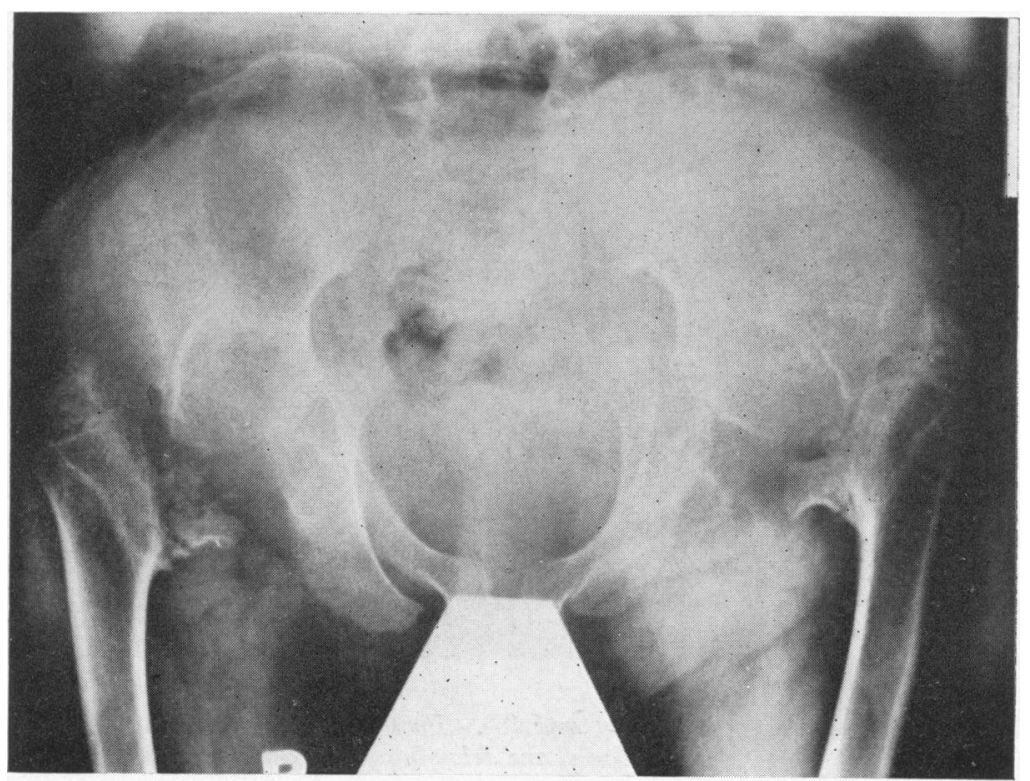



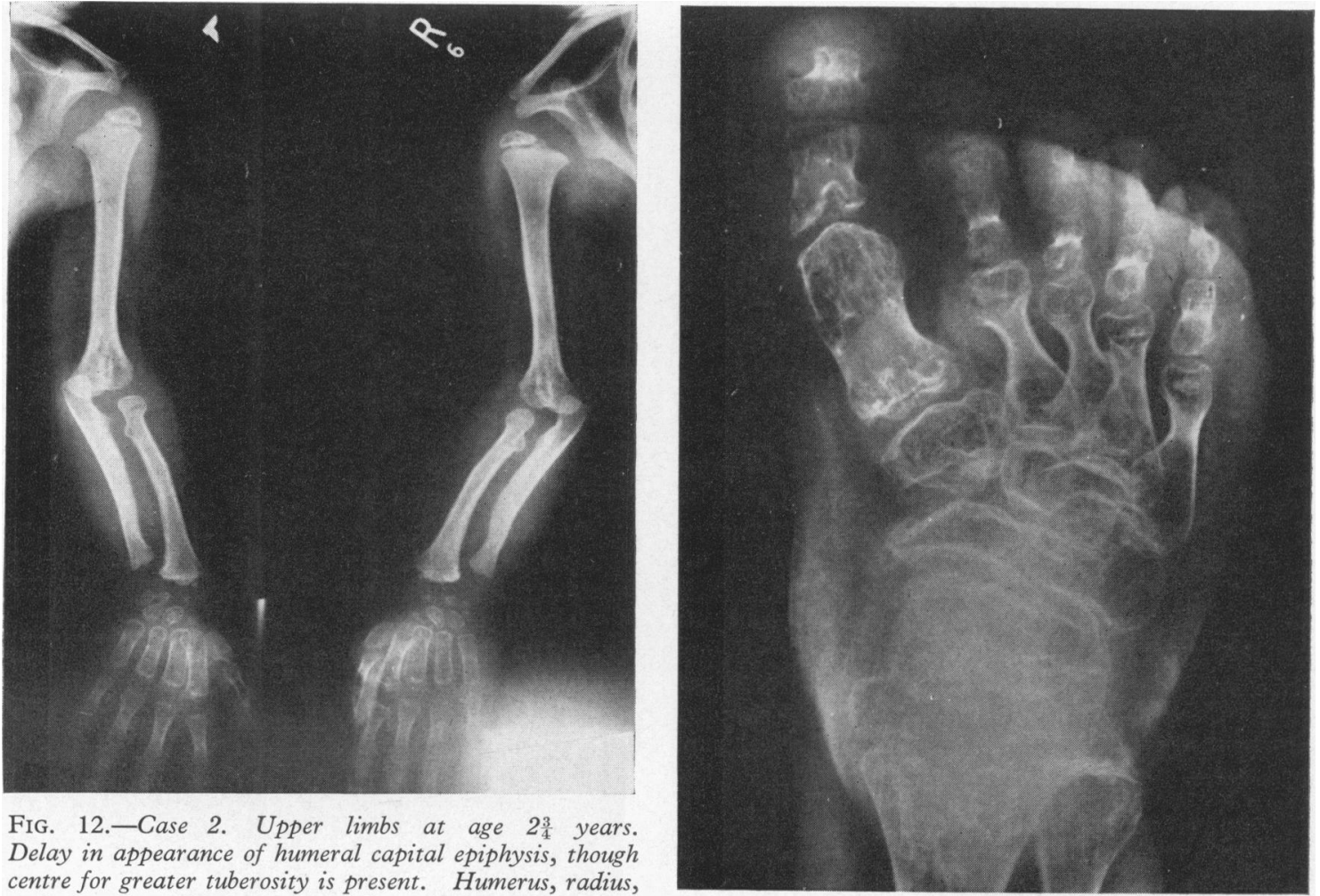

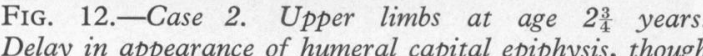
centre for greater tuberosity is present. Humerus, radius, and ulna are short, but the humerus is relatively less short. Hook-like projection on medial aspect of distal radial metaphysis.

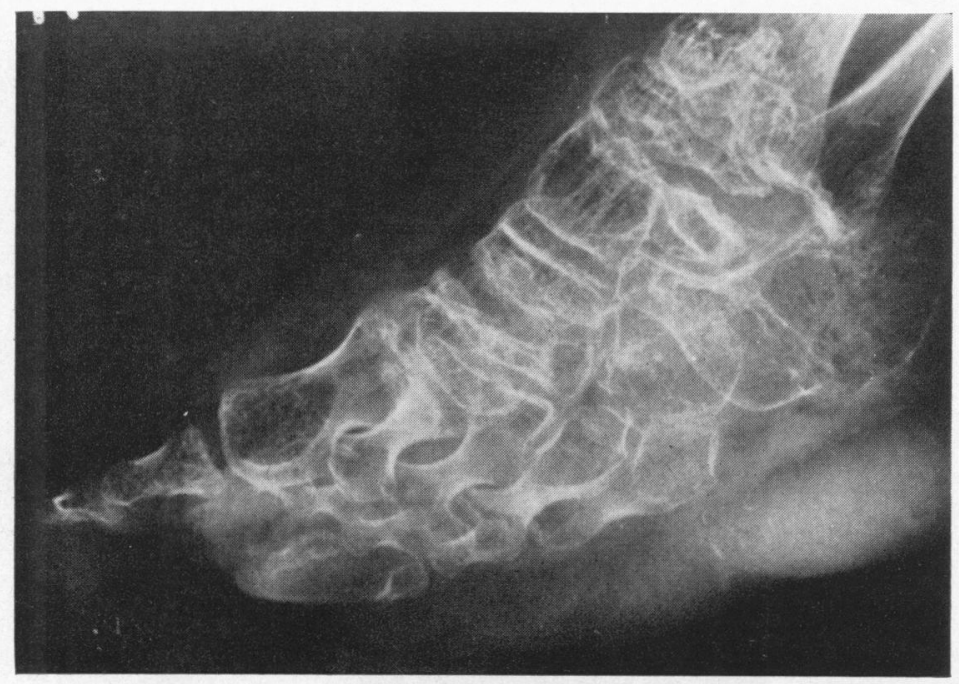

$13 \mathrm{~b}$

Fig. 13.-Case 1. (a) top right, and (b). Foot at age 83 years. Pes equinus, metatarsus varus, gross distortion of bones, and delay in appearance of secondary centres in the rays. 


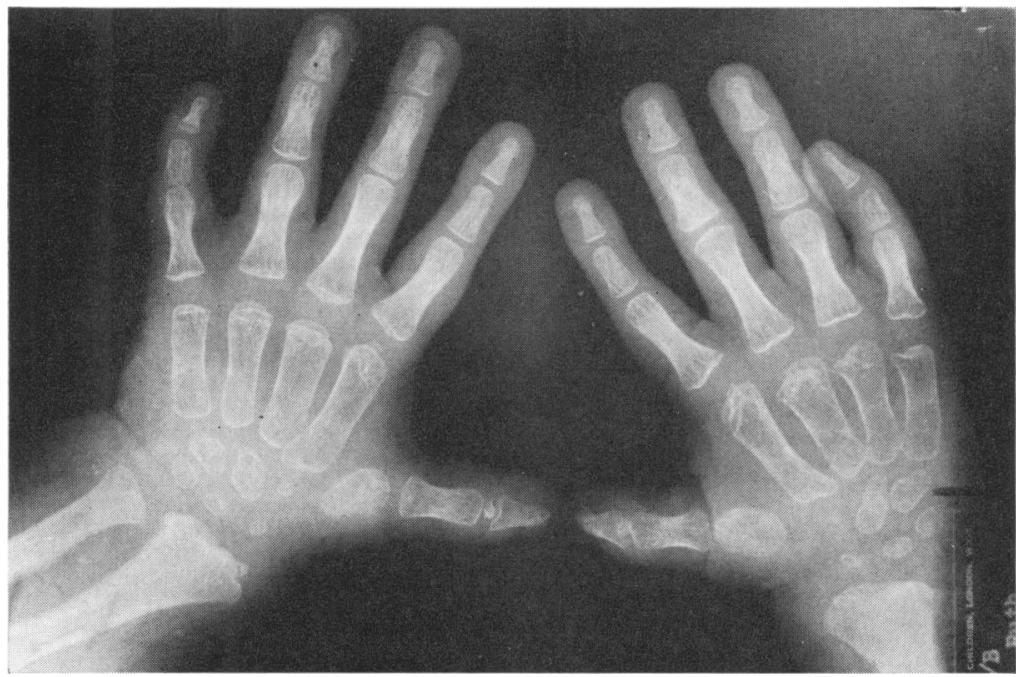

Fig. 14.-Case 2. Hands at age 23 years. Abducted thumb with short, oval first metacarpal, and appearance of 6 carpal bones with ring-like outlines. Only two secondary epiphysial centres are present in the 5 rays.

inheritance of the condition. None of the patients was the offspring of a consanguineous marriage, and of 4 sibs none was affected. Assuming that the hypothesis of recessive inheritance is correct, once parents have had one child with diastrophic dwarfism the risk of recurrence in each subsequent pregnancy is 1 in 4 . The risk to any other relatives is small, and sisters and brothers of a patient may be told that, provided that they do not marry a cousin, there is little chance of their having an affected child.

Treatment. This followed general orthopaedic lines, but in the 'stiff' cases the problems were formidable and comparable with those in an arthrogrypotic patient. For the talipes equinovarus deformities of Cases 1 and 2 operative treatment was both necessary and disappointing. Case 1 had two bony procedures and an elongation of the tendo Achillis on each side, and yet he had 20 to 30 degrees of fixed equinus deformity at 12 years of age. Case 2 had a soft tissue operation and two elongations of the tendo Achilles on each foot, and had obtained barely satisfactory results by the age of 3 years. In contrast, one soft tissue operation gave Case 3 good correction of the feet, and simple conservative therapy corrected those of Case 4: these are the 2 children that have been classified as 'lax' cases; both finished treatment with plantigrade mobile feet.

For knee flexion contracture, Case 1 had bilateral supracondylar osteotomies of femur. After these he still had 60 degrees of fixed flexion at both hip and knee. Further bony operations at the knee were under consideration. Correction of the hip contractures is also being considered, for these may well have influenced the recurrence of the knee deformity. Repeated bony procedures for knee flexion are difficult, and may give bizarre results if the joint contracture constantly recurs below the site of correction.

The finger extension contractures of Cases 1 and 2 have not been treated. It is difficult to envisage a course of treatment which could improve the facility with which these children use their hands.

\section{Summary}

Four cases of diastrophic dwarfism are presented. This is an autosomal recessive syndrome with a 1 in 4 risk to sibs. The condition has been confused with achondroplasia and Morquio's disease.

Clinical features are a normal head, short limbs, scoliosis, club foot, and joint contractures. There may be also a generalized joint laxity which influences the prognosis. Some patients have a cleft palate and develop swellings of the ears. The main radiological features are dislocations, and delay in appearance and poor development of many limb epiphyses. Spinal changes permit a distinction from achondroplasia and Morquio's disease. Persistent treatment of the contractures and scoliosis is necessary but is both difficult and disappointing. 
We are indebted to Professor A. W. Wilkinson, Mr. G. C. Lloyd Roberts, and Dr. P. R. Evans of The Hospital for Sick Children, Great Ormond Street, London, and to Mr. G. F. Walker of Queen Mary's Hospital for Children, Carshalton, for their kind permission to publish cases under their care.

\section{REFERENCES}

Amuso, S. J. (1968). Diastrophic dwarfism. f. Bone ft Surg., $\mathbf{5 0 A}, 113$.

Catel, W. (1951). Differentialdiagnostische Symptomatologie von Krankheiten des Kindesalters, 2nd ed. Thieme, Stuttgart.

Cobb, J. R. (1948). Outline for the study of scoliosis. The American Academy of Orthopaedic Surgeons Instructional Course Lectures. V., 261.

Helweg-Larsen, H. F., and Mørch, E. T. (1945). Genetic aspects of osteochondrodystrophy. Silfverskiöld's and Morquio's syndromes. Acta path. microbiol. scand., 22, 335.

Jackson, W. P. U. (1951). Irregular familial chondro-osseous defect. With suggestions concerning nomenclature of generalized osseous dystrophies. F. Bone ft Surg., 33B, 420.
Kaplan, M., Sauvegrain, J., Hayem, F., Drapeau, P., Maugey, F., and Boulle, J. (1961). Etude d'un nouveau cas de nanisme diastrophique. Arch. frans. Pédiat., 18, 981.

Kratz, R. C. (1956). Congenital perichondritis associated with achondroplasia. Laryngoscope (St Louis), 66, 93.

Lamy, M., and Maroteaux, P. (1960). La nanisme diastrophique. Presse méd., 68, 1977.

Langer, L. O., Jr. (1.965). Diastrophic dwarfism in early infancy. Amer. F. Roentgenol., 93, 399.

Lato, M., Severi, F., and Ceccarelli, A. (1957). Considerazioni cliniche su due casi di osteocondrodistrofie dell' accresimento. Aggiorn. pediat., 8, 189.

McKusick, V. A., and Milch, R. A. (1964). The clinical behavior of genetic disease. Selected aspects. Clinical Orthop., 33, 22.

Paul. S. S., Rao, P. L., Mullick, P., and Saigal, S. (1965). Diastrophic dwarfism. A little known disease entity. Clin. Pediat. (Phila.), 4, 95.

Rubin, P. (1964). Dynamic Classification of Bone Dysplasias, p. 167. Year Book Medical Publishers, Chicago.

Stover, C. N., Hayes, J. T., and Holt, J. F. (1963). Diastrophic dwarfism. Amer. F. Roentgenol., 89, 914.

Taybi, H. (1963). Diastrophic dwarfism. Radiology, 80, 1. 